\title{
Rate of ectasia and incidence of irregular topography in patients with unidentified preoperative risk factors undergoing femtosecond laser-assisted LASIK
}

\author{
This article was published in the following Dove Press journal: \\ Clinical Ophthalmology \\ 9 December 2013 \\ Number of times this article has been viewed
}

\author{
Majid Moshirfar' \\ Jared G Smedley ${ }^{2}$ \\ Valliammai Muthappan' \\ Allison Jarsted ${ }^{3}$ \\ Erik M Ostler' \\ 'John A Moran Eye Center, University \\ of Utah, Salt Lake City, UT, USA; \\ ${ }^{2}$ College of Human Medicine, Michigan \\ State University, Lansing, MI, USA; \\ ${ }^{3}$ Department of Ophthalmology, \\ State University of New York Upstate \\ Medical University, Syracuse, NY, USA
}

Correspondence: Majid Moshirfar John A Moran Eye Center, Old Mill Medical Center, 6360 South 3000 East, Suite 200, Salt Lake City,

Utah 84I2I, USA

$\mathrm{Tel}+\mathrm{I} 8015853937$

Fax + I 80I 9479286

Email majid.moshirfar@hsc.utah.edu
Purpose: To report the rate of postoperative ectasia after laser-assisted in situ keratomileusis (LASIK) with femtosecond laser-assisted flap creation, in a population of patients with no identified preoperative risk factors.

Methods: A retrospective case review of 1,992 eyes (1,364 patients) treated between March 2007 and January 2009 was conducted, with a follow up of over 4 years. After identifying cases of ectasia, all the patient charts were examined retrospectively for preoperative findings suggestive of forme fruste keratoconus (FFKC).

Results: Five eyes of four patients with post-LASIK ectasia were identified. All eyes passed preoperative screening and received bilateral LASIK. One of the five patients developed ectasia in both eyes. Three patients retrospectively revealed preoperative topography suggestive of FFKC, while one patient had no identifiable preoperative risk factors. Upon review of all the charts, a total 69 eyes, including four of the five eyes with ectasia, were retrospectively found to have topographies suggestive of FFKC.

Conclusion: We identified four cases of post-LASIK ectasia that had risk factors for FFKC on reexamination of the chart and one case of post-LASIK ectasia with no identifiable preoperative risk factors. The most conservative screening recommendations would not have precluded this patient from LASIK. The rate of purely iatrogenic post-LASIK ectasia at our center was $0.05 \%(1 / 1,992)$, and the total rate of post-LASIK ectasia for our entire study was $0.25 \%$ (1/398). The rate of eyes with unrecognized preoperative FFKC that developed post-LASIK ectasia was $5.8 \%(1 / 17)$.

Keywords: LASIK, ectasia, visual acuity, forme fruste keratoconus, topography

\section{Introduction}

Laser in situ keratomileusis (LASIK) has long been well established as a safe and effective corrective procedure for patients with refractive error. Complications are rare but can be visually devastating, particularly in the case of iatrogenic keratectasia. Postoperative ectasia results in severe, progressive myopic astigmatism that is traditionally considered to be irreversible. The development of postoperative ectasia varies between LASIK centers and depends on the screening tools used to screen candidates, the experience and technical skill of the surgeon, and the tools used during the surgery. Risk factors for the development of post-LASIK ectasia include a personal or family history of keratoconus, forme fruste keratoconus (FFKC), high myopia, low-residual stromal bed (RSB), ${ }^{1,2}$ and deep primary keratotomy resulting in a thick flap. ${ }^{3}$ Patients who develop ectasia will 
often show one or more of these risk factors upon review; however, patients with no risk factors have also developed ectasia following LASIK. 4,5

As recently as 2007, over half of the surgical centers surveyed in the United States were using the traditional mechanical microkeratome for LASIK flap creation, which has been shown to produce unpredictable cut depths and variable flap thickness. ${ }^{6-8}$ In the last half decade, there has been a shift towards femtosecond laser-assisted flap creation, which provides a more predictable flap profile. ${ }^{9,10}$ In this study, we examined the rate of ectasia in patients undergoing femtosecond laser-assisted LASIK as well as the incidence of abnormal topography, in patients who were identified as having no preoperative risk factors.

\section{Methods and patients}

A retrospective chart analysis was performed at the John A Moran Eye Center (Department of Ophthalmology and Visual Science, University of Utah), identifying 1,992 eyes of 1,364 patients who underwent femtosecond laser-assisted LASIK from March 11, 2007 to January 19, 2009, a time period of approximately 22.5 months. Patient data was examined, and follow up was assessed over a period of 4 years. The population consisted of 1,115 eyes from females (56\%) and 877 eyes from males (44\%), with an average patient age of $39 \pm 5.17$ years (range 21-52 years). Prior to surgery, all eyes were screened for keratoconus and the presence of associated risk factors, using slit-lamp examination, retinoscopy, topography, and Rabinowitz criteria. ${ }^{11-13}$ All patients were asked about a family history of keratoconus, and topographic analysis was done, using the Orbscan ${ }^{\circledR} \mathrm{IIz}$ (Bausch and Lomb, Inc, Rochester, NY, USA), to screen all eyes for asymmetry, nonorthogonal bowties, or skewed radial axes. Corneal keratometry values were measured using an Atlas $^{\text {TM }} 9000$ Corneal Topographer (Carl Zeiss Meditec Inc, Jena, Germany). All surgeries were performed by creation of a corneal flap with the IntraLase ${ }^{\mathrm{TM}} \mathrm{FS}$ femtosecond laser (Abbott Medical Optics, Inc, Santa Ana, CA, USA) and with stromal ablation by the Visx Star S4 IR ${ }^{\text {TM }}$ excimer laser (Abbott Medical Optics, Inc). In all cases, the right eye was operated on first, followed by the left eye. Intraoperative ultrasound pachymetry was not performed.

In this study, all of the patient charts were scrutinized postoperatively for evidence of preoperative risk factors, such as a family history of keratoconus, abnormal slit-lamp examinations, suspicious inferior steepening, and findings suggestive of FFKC as defined by Rabinowitz and McDonnell (central corneal power $>47.2 \mathrm{D}$ or inferosuperior asymmetry value $>1.4$ D). ${ }^{12-14}$ In a manner similar to Randleman et al, ${ }^{1}$ we defined postoperative ectasia as an inferior topographic steepening of $5 \mathrm{D}$ or more compared with immediate postoperative topographies, along with a decrease in uncorrected visual acuity (UCVA) of two or more lines on the Snellen chart. We defined rate as the number of occurrences of ectasia at any time following LASIK surgery per number of eyes.

\section{Case reviews}

\section{Case I (eye I)}

A 20-year-old woman underwent bilateral LASIK in July 2007. By 21 months postop, the patient began to experience blurred vision OD, with UCVA of 20/30 in the right eye (OD) and 20/20 in the left eye (OS); the best corrected visual acuity (BCVA) was 20/20 OD and 20/15 OS, and corneal topography showed inferonasal steepening OD (Figure 1), with a normal post-LASIK appearance OS. At the most recent follow up, the UCVA was 20/50 OD and BCVA was 20/25. Topography demonstrated inferonasal corneal ectasia OD, with simulated keratometry (SimK) measurements of 42.12/48.75 and Orbscan pachymetry thickness of $392 \mathrm{~mm}$ $\mathrm{OD}$ at the tip of the cone. The postoperative course of her left eye remained uncomplicated. The patient currently wears a rigid gas permeable lens in her right eye.

The postoperative retrospective chart review revealed FFKC bilaterally, with an acceptable central corneal power $(<47.2 \mathrm{D})$ and an inferosuperior asymmetry value of $3.0 \mathrm{D}$ in the affected eye (Figure 2). There was no noted family history of keratoconus.

\section{Case 2 (eye 2)}

A 39-year-old woman underwent bilateral LASIK in January 2008. At 44 months after surgery, the patient complained of decreased vision in her right eye. At that time, the patient

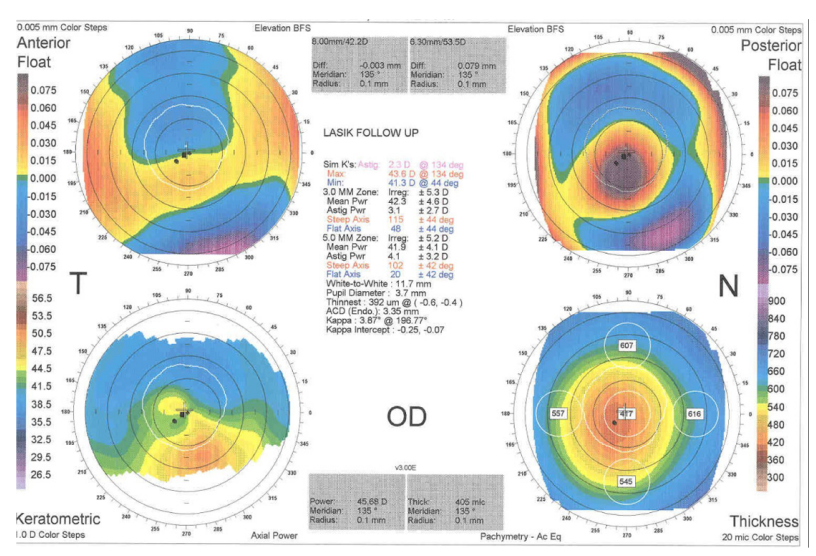

Figure I Orbscan ${ }^{\circledR}$ (Bausch and Lomb, Inc, Rochester, NY, USA) image of patient I, showing inferior ectasia in the right eye 21 months postoperatively. 


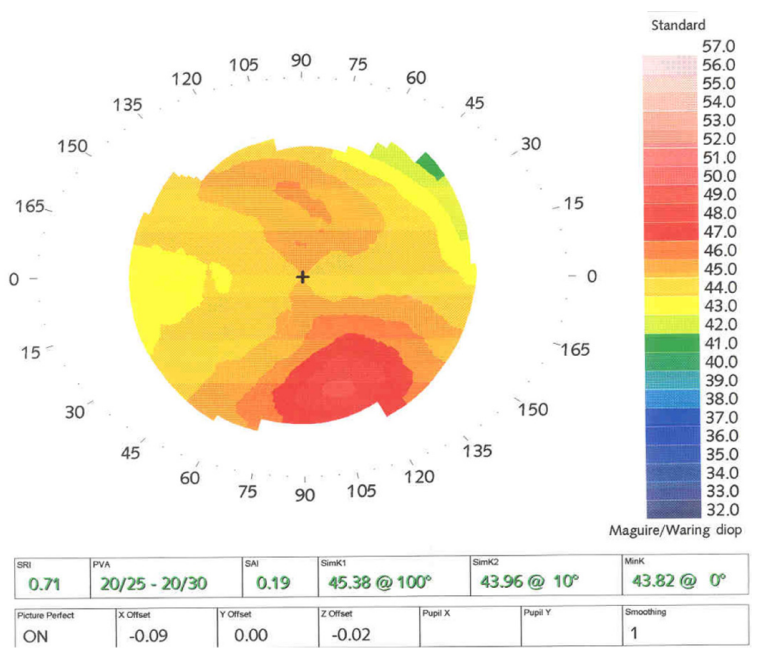

Figure 2 Preoperative Atlas ${ }^{\mathrm{TM}}$ (Carl Zeiss Meditec Inc, Jena, Germany) topography of patient I, demonstrating inferior steepening of right eye.

had UCVA of 20/30 in each eye and BCVA of 20/30 OD and $20 / 20$ OS. The result of the Orbscan study showed signs of inferior steepening OD (Figure 3) and a normal post-LASIK central flattening OS. The most recent postoperative evaluation showed UCVA of 20/30 OD and 20/25 OS. The keratometry measured 40.90/43.80 OD and 41.80/43.10 OS, with Orbscan pachymetries of $421 \mu \mathrm{m}$ OD and $407 \mu \mathrm{m}$ OS. She currently wears spectacles to achieve BCVA.

The postoperative retrospective chart review revealed inferior steepening in the right eye (Figure 4) as well as a preoperative pachymetry measurement of $458 \mu \mathrm{m}$ and a RSB of $254 \mu \mathrm{m}$ in this eye, which suggests a previously unrecognized FFKC. There was no noted family history of keratoconus.

\section{Case 3 (eyes 3 and 4)}

A 34-year-old female underwent bilateral LASIK in December 2008. At 12 months postop, the patient complained

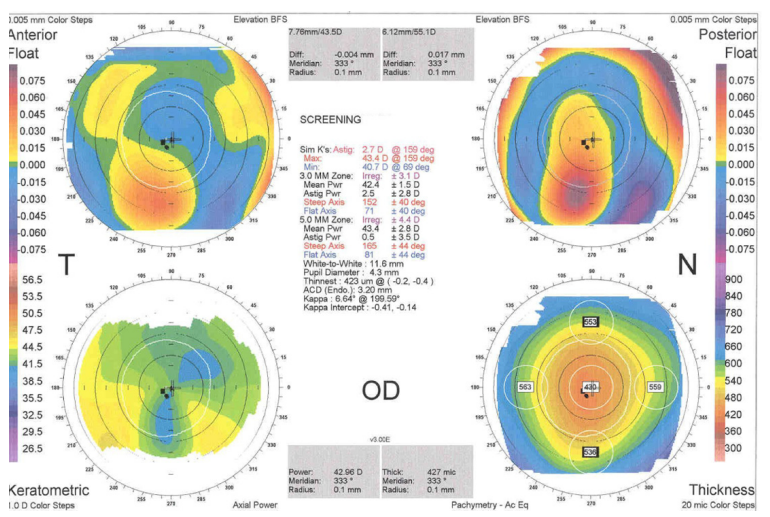

Figure 3 Orbscan $^{\circledR}$ (Bausch and Lomb, Inc, Rochester, NY, USA) image demonstrating inferior ectasia in the right eye at postoperative month 44 in patient 2.
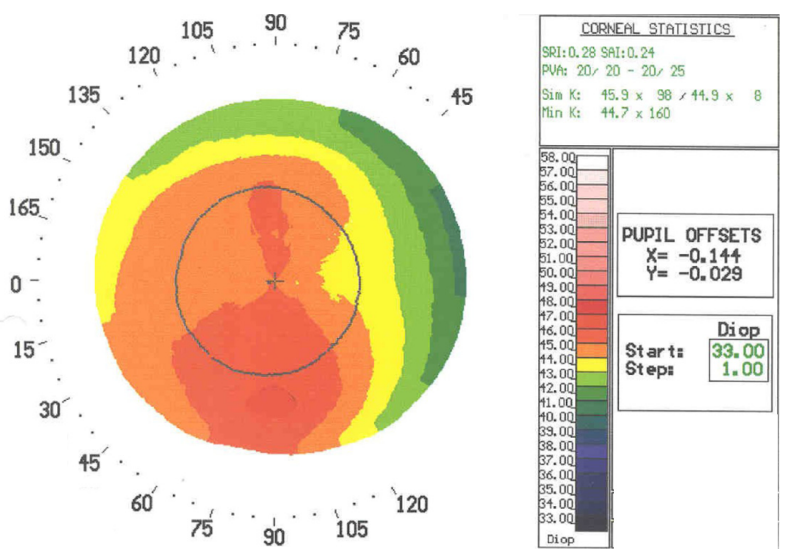

Figure 4 Atlas $^{\text {TM }}$ (Carl Zeiss Meditec Inc, Jena, Germany) topography demonstrating right eye inferior steepening preoperatively in patient 2 .

of progressive blurring in both eyes. The UCVA was 20/50 OD and 20/80 OS, and the BCVA was 20/20 OD and 20/25 OS. The Orbscan revealed inferior steepening bilaterally (Figure 5). The UCVA at the most recent follow up, at 32 months postop, was 20/60 in both eyes (OU). Keratometry at this visit measured 40.60/42.00 OD and 41.20/42.80 OS (Figure 6), with Orbscan pachymetry of $479 \mu \mathrm{m}$ OD and $462 \mu \mathrm{m}$ OS. The patient currently has a spectacle-corrected BCVA of 20/25 OD and 20/15 OS.

As in cases 1 and 2, a retrospective review of the preoperative corneal topography demonstrated inferior steepening bilaterally (Figures 7 and 8 ). There was no noted family history of keratoconus.

\section{Case 4 (eye 5): unilateral corneal ectasia} with no identifiable preoperative risk factors

A 30-year-old male underwent bilateral LASIK in June 2007. At 20 months postprocedure, the patient experienced progressive blurring in his left eye. The UCVA was 20/25 OD and 20/150 OS, with a BCVA of 20/20 OU, corresponding

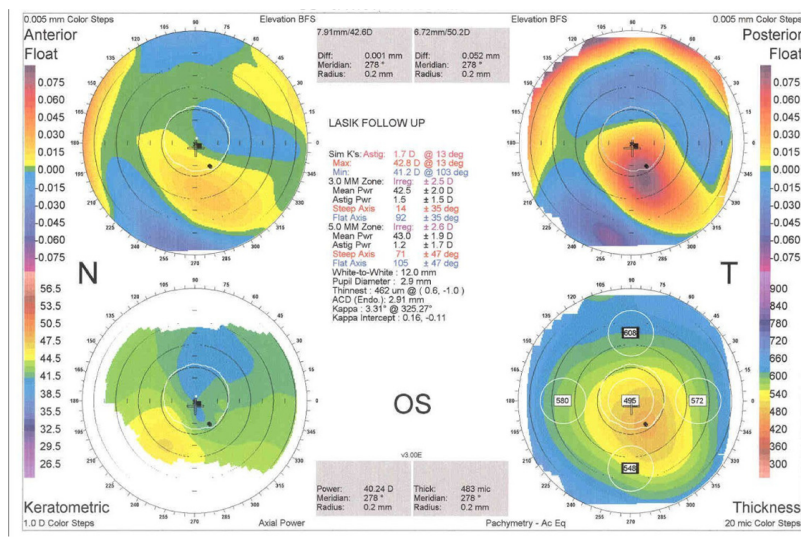

Figure 5 Orbscan ${ }^{\circledR}$ (Bausch and Lomb, Inc, Rochester, NY, USA) image demonstrating inferior steepening of the left eye at 12 months postoperatively in patient 3. 


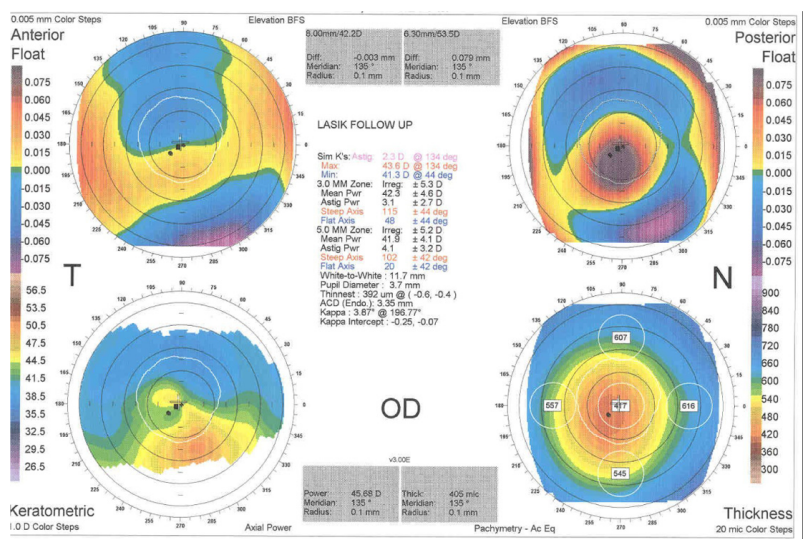

Figure 6 Orbscan ${ }^{\circledR}$ (Bausch and Lomb, Inc, Rochester, NY, USA) demonstrating inferior ectasia in the right eye at 32 months postoperatively in patient 3 .

to a manifest refraction of $-0.50+0.75 \times 153$ OD and -4.50 $+3.25 \times 030$ OS.

By 22 months he complained of progressive blurring of his left eye. The UCVA was 20/200 OS and BCVA was $20 / 25$, with an increase in average keratometry from 40.30 $\mathrm{D}$ to $42.37 \mathrm{D}$. Corneal topography showed significant inferior ectasia (Figure 9), and Orbscan pachymetry measured $523 \mu \mathrm{m}$. The patient currently wears rigid gas permeable contact lenses to achieve a BCVA of 20/20 OS.

The retrospective review of the preoperative data showed relatively normal topography with no clear indication of keratoconus and no other risk factors for the development of postoperative ectasia (Figure 10). There was no noted family history of keratoconus.

\section{Results}

Over a period of 10.5 months, 1,992 femtosecond assisted LASIK procedures were performed at our institution. No intraoperative complications occurred during the time

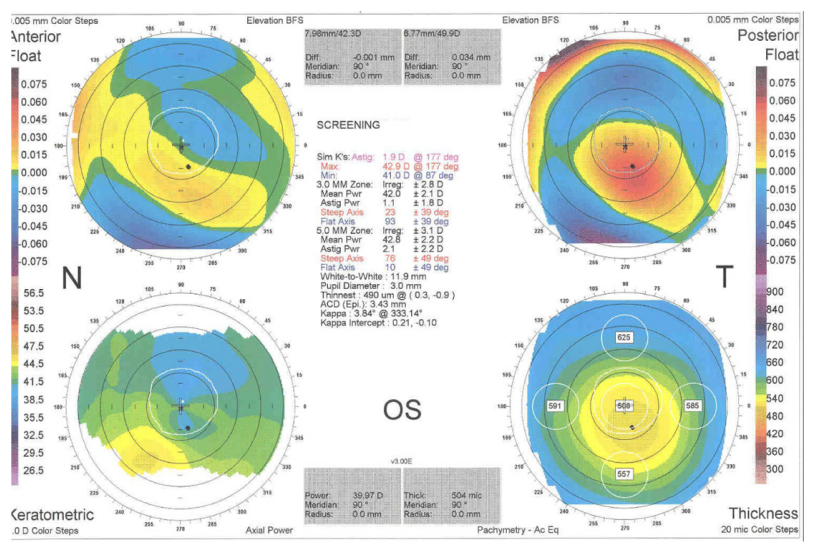

Figure 7 Orbscan ${ }^{\circledR}$ (Bausch and Lomb, Inc, Rochester, NY, USA) showing inferior steepening preoperatively in the left eye of patient 3.

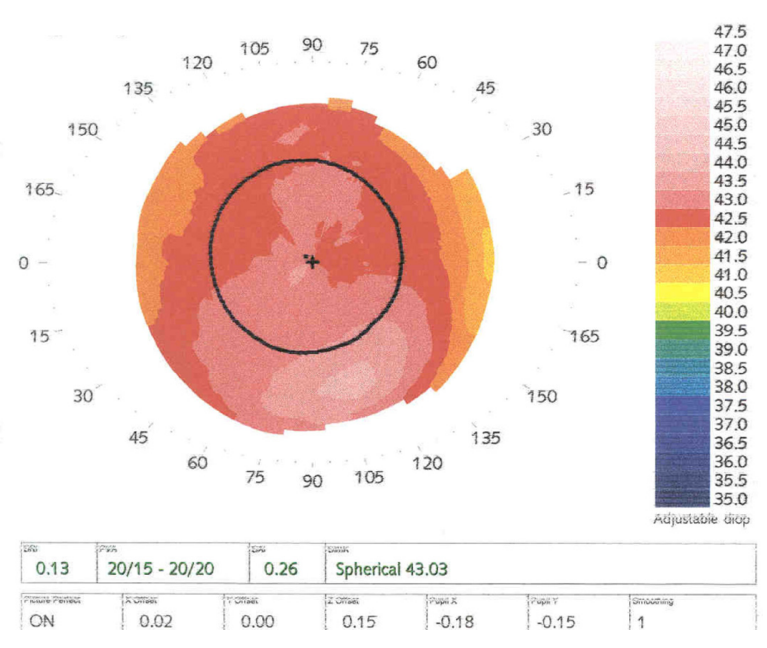

Figure 8 Atlas $^{\mathrm{TM}}$ (Carl Zeiss Meditec Inc, Jena, Germany) topography showing inferior steepening preoperatively in the right eye of patient 3.

period of the study. The chart and topography review of all 1,992 eyes revealed that five eyes of four patients developed postprocedure ectasia. Based on the preoperative topographical review, it was determined that four of the five eyes with ectasia had topographical shifts suggestive of FFKC that passed initial screening, while one eye showed no clearly identifiable preoperative risk factors. In addition, 69 eyes, including four eyes with post-LASIK ectasia, were also found to have abnormal topographies suggestive of FFKC. Of these 69 eyes, there were 43 eyes from females (62\%) and 26 eyes from males (38\%), with an average patient age of $38 \pm 4.50$ years (range $21-48$ years). The preoperative characteristics can be seen in Table 1.

In our study, the rate of post-LASIK ectasia in patients with no identifiable risk factors was one case of ectasia per 1,922 eyes, or $0.05 \%$ ( 69 eyes were subtracted from the total

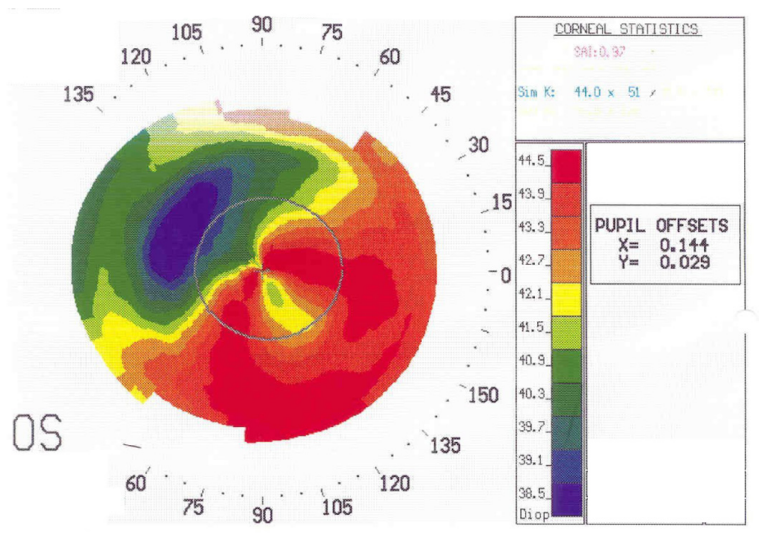

Figure 9 Inferior ectasia seen in patient 4's left eye 22 months postoperatively, by Atlas $^{\text {TM }}$ (Carl Zeiss Meditec Inc, Jena, Germany) topography scan. 


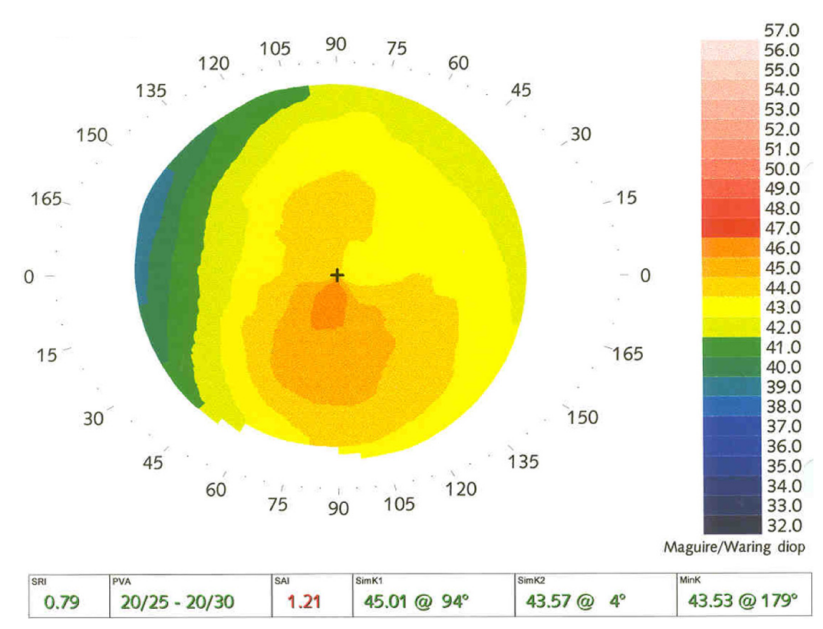

Figure 10 Normal preoperative topography of patient 4's left eye as seen on Atlas $^{\mathrm{TM}}$ (Carl Zeiss Meditec Inc, Jena, Germany) topography scan.

due to identified preoperative risk of abnormal topography). Retrospectively, 69 eyes (3.5\%) had preoperative topographies that were suggestive of FFKC. Four of these 69 eyes developed postoperative corneal ectasia, with a rate of one case of ectasia per 17 eyes (5.8\%) in patients with unrecognized FFKC preoperatively. The rate of post-LASIK ectasia in eyes due to all causes was one case of ectasia per 398 eyes $(0.25 \%)$. The average time to detection of post-LASIK ectasia in our study was $18.8 \pm 6.51$ months after surgery (range 5 to 44 months). The postoperative visual outcomes are seen in Table 2.

\section{Discussion}

The development of corneal ectasia is a well-known and visually devastating complication of LASIK surgery., ${ }^{4,12,-24}$ In our study, we evaluated the rate of this complication after the implementation of the femtosecond laser for the creation of the LASIK flap. Abnormal topography was the most common risk factor, with four of the five eyes displaying this on the retrospective review of their charts. This has been reported in up to $50 \%$ of patients with iatrogenic ectasia..$^{25,26}$

Thinning of the cornea is one of the initial changes in ectasia and keratoconus. ${ }^{27}$ Of the four eyes with postoperatively identified abnormal topography, two eyes also had preoperative ultrasound pachymetry measurements just below the recommended value of $500 \mu \mathrm{m}$. According to the Randleman criteria, ${ }^{1}$ these two patients (three eyes) had two risk factors for developing ectasia: FFKC and reduced corneal thickness. The common methods for measuring central corneal thickness include ultrasound pachymetry, optical coherence tomography (OCT), and scheimpflug imaging Pentacam $^{\circledR}$ (Oculus Optikgeräte GmbH, Wetzlar, Germany);

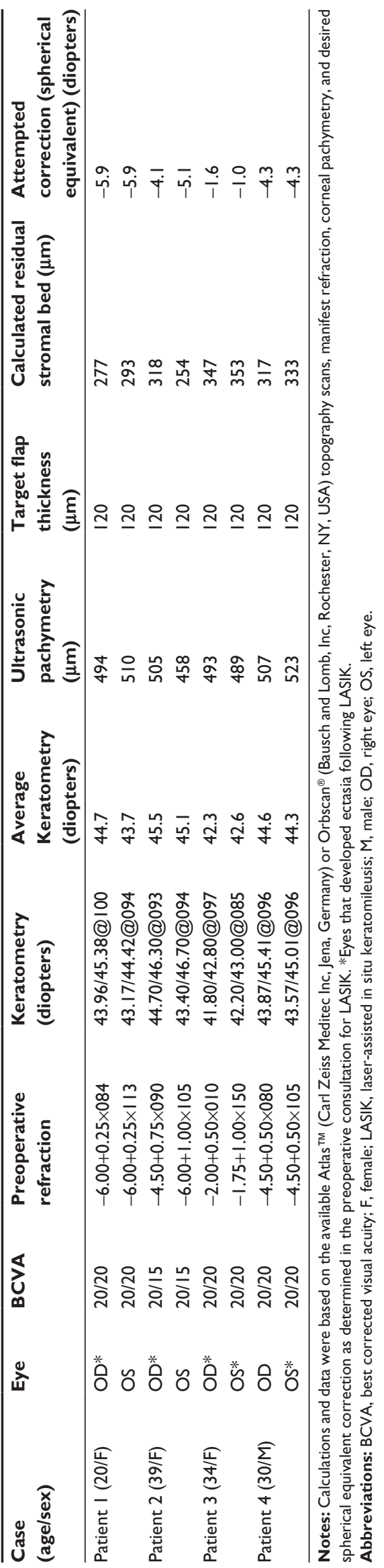


Table 2 Postoperative clinical data at 3 months post-LASIK and at the most recent follow up on record

\begin{tabular}{|c|c|c|c|c|c|c|c|c|c|}
\hline \multirow{2}{*}{$\begin{array}{l}\text { Cases (agel } \\
\text { sex) }\end{array}$} & \multirow[t]{2}{*}{ Eye } & \multicolumn{3}{|c|}{ 3-month post-LASIK follow-up visit } & \multicolumn{5}{|c|}{ Most recent follow-up visit } \\
\hline & & $\begin{array}{l}\text { Manifest } \\
\text { refraction }\end{array}$ & $\begin{array}{l}\text { Keratometry } \\
\text { (diopters) }\end{array}$ & $\begin{array}{l}\text { Average } \\
\text { keratometry } \\
\text { (diopters) }\end{array}$ & UCVA & BCVA & $\begin{array}{l}\text { Manifest } \\
\text { refraction }\end{array}$ & $\begin{array}{l}\text { Keratometry } \\
\text { (diopters) }\end{array}$ & $\begin{array}{l}\text { Average } \\
\text { keratometry } \\
\text { (diopters) }\end{array}$ \\
\hline \multirow[t]{2}{*}{$\begin{array}{l}\text { Patient I } \\
(20 / F)\end{array}$} & OD* & $-0.75 \mathrm{DS}$ & 38.73/39.63@108 & 39.2 & $20 / 50$ & $20 / 25$ & $\begin{array}{l}-1.75+3.50 \\
\times 157\end{array}$ & 42.12/48.75@070 & 45.4 \\
\hline & OS & plano & 38.76/39.68@069 & 39.2 & $20 / 25$ & $20 / 15$ & $-1.00 \mathrm{DS}$ & 38.12/39.50@074 & 38.8 \\
\hline \multirow[t]{2}{*}{$\begin{array}{l}\text { Patient } 2 \\
(39 / F)\end{array}$} & OD* & $\begin{array}{l}\text { plano }+0.50 \\
\times 1 / 0\end{array}$ & 4I.10/42.10@100 & 41.6 & $20 / 30$ & $20 / 20$ & $\begin{array}{l}-0.25+0.75 \\
\times 133\end{array}$ & 40.90/43.80@।57 & 42.4 \\
\hline & OS & $\begin{array}{l}\text { plano }+0.75 \\
\times 110\end{array}$ & 40.20/42.10@।10 & $4 I .1$ & $20 / 25$ & $20 / 20$ & $\begin{array}{l}-0.75+0.75 \\
\times 070\end{array}$ & 4I.80/43.10@07I & 42.5 \\
\hline \multirow[t]{2}{*}{$\begin{array}{l}\text { Patient } 3 \\
(34 / F)\end{array}$} & OD* & $\begin{array}{l}\text { plano }+0.50 \\
\times 015\end{array}$ & 40.30/4I.10@I50 & 40.9 & $20 / 60$ & $20 / 20$ & $\begin{array}{l}-0.75+2.25 \\
\times 170\end{array}$ & 40.60/42.00@168 & 41.3 \\
\hline & OS* & $\begin{array}{l}-1.75+1.75 \\
\times 152\end{array}$ & 4I.10/42.10@003 & 41.6 & $20 / 60$ & $20 / 20$ & $\begin{array}{l}-1.25+2.50 \\
\times 163\end{array}$ & 41.20/42.80@0।3 & 42.0 \\
\hline \multirow[t]{2}{*}{$\begin{array}{l}\text { Patient } 4 \\
(30 / \mathrm{M})\end{array}$} & OD & $-0.25 \mathrm{DS}$ & 40.15/4I.21@105 & 40.6 & $20 / 25$ & $20 / 20$ & $\begin{array}{l}-0.25+1.00 \\
\times 140\end{array}$ & 38.75/4I.75@|22 & 40.3 \\
\hline & OS* & plano & 39.88/40.70@072 & 40.3 & $20 / 200$ & $20 / 25$ & $\begin{array}{l}-3.75+2.75 \\
\times 045\end{array}$ & 39.50/45.25@045 & 42.4 \\
\hline
\end{tabular}

Notes: The examination data and topography was collected at follow up 3 months post-LASIK. The final examination data and keratometry readings were determined by the most recent (or current) follow-up data on record after the diagnosis of ectasia. The examinations included visual acuities, refractions, and topographies performed with either an Atlas ${ }^{\mathrm{TM}}$ (Carl Zeiss Meditec Inc, Jena, Germany) or Orbscan ${ }^{\circledR}$ (Bausch and Lomb, Inc, Rochester, NY, USA) device. *Eyes that developed ectasia following LASIK. Similar to Randleman,' we defined postoperative ectasia as an inferior topographic steepening of $5 \mathrm{D}$ or more compared with immediate postoperative topographies, along with a decrease in uncorrected visual acuity of two or more lines on the Snellen chart.

Abbreviations: BCVA, best corrected visual acuity; F, female; LASIK, laser-assisted in situ keratomileusis; M, male; OD, right eye; OS, left eye; UCVA, uncorrected visual acuity.

significant variations in accuracy and reproducibility have been seen between these different modalities and within the same modality, in repeated measurements. Thus it is difficult to define hard screening criteria for central corneal thickness. $^{28}$

When retrospectively applying the Randleman criteria to our study, four ectatic eyes were established to be high risk, while one eye with ectasia showed little to no preoperative risk. Intraoperatively, flap thickness and RSB thickness were not measured for these patients. RSB and flap thickness are known risk factors for the development of ectasia, with $^{23,24}$ thicker flaps reducing the amount of tissue available for excimer ablation and final RSB thickness. ${ }^{25,28-30}$ Until recently, mechanical microkeratome was the primary method for flap creation, and flap thickness has varied greatly depending on the brand and plate size of the microkeratome. ${ }^{31-33}$ Despite improvements in consistency, there has still been significant variability in both the mean and range of flap thickness. ${ }^{6-8,34,35}$ One report attributed a case of post LASIK ectasia to a microkeratome-created flap with thickness of $225 \mu \mathrm{m}$ that was intended to be $160 \mu \mathrm{m}$. It may be beneficial to measure flap thickness and RSB intraoperatively, to identify cases that may be at risk for postoperative ectasia despite a lack of risk on preoperative evaluation. The femtosecond laser has more reliability than the microkeratome in creating flaps of consistent thickness; however, it is not unfailing, and some cases of ectasia may be due to a thicker-than-intended flap, even with laser-assisted flap creation.

Since 2008, the femtosecond laser has become the primary method for flap creation in the US, ${ }^{36}$ with improved consistency of flap size, depth, and circularity. This reliability is particularly valuable for thin flap LASIK (90-120 micron thickness) techniques, which have been shown to limit the reduction in corneal tensile strength., ${ }^{9,37}$ The overall rate of ectasia has anecdotally been on the decline; however, due to the rarity of cases, the evidence of an overall trend is lacking. Klein et al have estimated a rate of $0.04 \%$, or one in 2,500 cases, for microkeratome-assisted LASIK, ${ }^{38}$ and other reports show rates of ectasia up to $0.9 \% .^{26,38-42}$ There are often limitations to the interpretations of the reported data, such as inadequate follow up or poor generalizability. $\mathrm{A2}$ strength of our study is the wide variety of preoperative refractive error in our patients, the high rate of follow up over 4 years, and the consistency of all procedures (that were performed in a single facility, using the same IntraLase femtosecond laser for flap creation).

Regarding low-risk patients with ectasia, a prior study has suggested that approximately one out of every 1,000 patients $(0.1 \%)$ who have undergone LASIK with microkeratome flap may later be identified as developing ectasia despite little to no identifiable preoperative risk..$^{39}$ In our study, approximately 
one out of every 2,000 patients $(0.05 \%)$ who underwent LASIK with femtosecond laser-assisted flap may be identified as developing ectasia with little to no preoperative risk. This represents a $50 \%$ rate reduction.

Interestingly, 69 eyes with abnormal topography underwent LASIK at our center, even after undergoing the rigorous preoperative screening. All of these cases were retrospectively identified as high risk, with a Randleman score of 4, excluding any other coexisting risk factors. However, only four of these eyes developed ectasia. This suggests that $94.2 \%$ of patients excluded from LASIK based on topography alone would not develop ectasia for 4 years. It is possible that these patients have not yet developed ectasia, and longer follow up of this group is warranted. Additionally, this highlights the need for more sensitive and specific tests to detect ectasia risk.

This study sought to determine the rate of iatrogenic ectasia in patients undergoing LASIK with femtosecond laser-assisted flap formation. The most significant limitation to this study was the lack of adequate date-matched studies addressing the rate of ectasia among cases of LASIK with mechanical microkeratome flap creation versus femtosecond laser-assisted LASIK. The best comparable study we found displays a cohort that underwent LASIK a minimum of 4 years before LASIK was performed in our population. ${ }^{40}$ This study showed twice the rate of ectasia formation; however, one limitation to this interpretation is that changes in surgical techniques, heightened awareness and vigilance for risk factors, and general advances in other technologies over time, may have played a significant role in the difference in rate between the two studies. For example, newer screening modalities, using instruments such as the Pentacam or Visante OCT (Carl Zeiss Meditec, Inc), have proven better reproducibility of central corneal thickness measurements over ultrasound pachymetry. Additionally, we are comparing studies of procedures performed at one facility to those performed at another facility; each of these facilities may treat a special patient population that may not be entirely representative of the general population. All studies on iatrogenic ectasia suffer from the rarity of such cases and a delayed time to presentation complicated by a short follow up, leading to an underreporting of cases. Our study is stronger than most in this regard, due to the 4 years of follow up but still suffers from the small number of cases diagnosed with postprocedure ectasia.

A multicenter prospective longitudinal study of LASIK performed with mechanical microkeratome versus femtosecond laser would be most effective in comparing real-world outcomes among LASIK patients but may be unrealistic due to the increased popularity of femtosecond lasers and the general belief that they are safer than microkeratomes. We propose that in addition to its other benefits, femtosecondassisted laser also decreases the incidence of iatrogenic keratectasia, when compared with microkeratome-assisted procedures.

\section{Acknowledgment}

The study was supported, in part, by a grant to the Department of Ophthalmology at the University of Utah, Salt Lake City, from Research to Prevent Blindness.

\section{Disclosure}

The authors report no conflicts of interest in this work.

\section{References}

1. Randleman JB, Russell B, Ward MA, Thompson KP, Stulting RD. Risk factors and prognosis for corneal ectasia after LASIK. Ophthalmology. 2003;110(2):267-275.

2. Chang AW, Tsang AC, Contreras JE, et al. Corneal tissue ablation depth and the Munnerlyn formula. J Cataract Refract Surg. 2003;29(6): 1204-1210.

3. Haw WW, Manche EE. Iatrogenic keratectasia after a deep primary keratotomy during laser in situ keratomileusis. Am J Ophthalmol. 2001;132(6):920-921

4. Amoils SP, Deist MB, Gous P, Amoils PM. Iatrogenic keratectasia after laser in situ keratomileusis for less than -4.0 to -7.0 diopters of myopia. J Cataract Refract Surg. 2000;26(7):967-977.

5. Geggel HS, Talley AR. Delayed onset keratectasia following laser in situ keratomileusis. J Cataract Refract Surg. 1999;25(4):582-586.

6. Binder PS, Moore M, Lambert RW, Seagrist DM. Comparison of two microkeratome systems. J Refract Surg. 1997;13(2):142-153.

7. Pérez-Santonja JJ, Bellot J, Claramonte P, Ismail MM, Alió JL. Laser in situ keratomileusis to correct high myopia. J Cataract Refract Surg. 1997;23(3):372-385.

8. Shemesh G, Dotan G, Lipshitz I. Predictability of corneal flap thickness in laser in situ keratomileusis using three different microkeratomes. J Refract Surg. 2002;18(Suppl 3):S347-S351.

9. Zhang Y, Chen YG, Xia YJ. Comparison of corneal flap morphology using AS-OCT in LASIK with the WaveLight FS200 femtosecond laser versus a mechanical microkeratome. J Refract Surg. 2013;29(5): 320-324.

10. Kymionis GD, Kankariya VP, Plaka AD, Reinstein DZ. Femtosecond laser technology in corneal refractive surgery: a review. J Refract Surg. 2012;28(12):912-920

11. Binder PS, Lindstrom RL, Stulting RD, et al. Keratoconus and corneal ectasia after LASIK. J Cataract Refract Surg. 2005;31(11):2035-2038.

12. Rabinowitz YS, McDonnell PJ. Computer-assisted corneal topography in keratoconus. Refract Corneal Surg. 1989;5(6):400-408.

13. Rabinowitz YS. Videokeratographic indices to aid in screening for keratoconus. J Refract Surg. 1995;11(5):371-379.

14. Maeda N, Klyce SD, Smolek MK. Comparison of methods for detecting keratoconus using videokeratography. Arch Ophthalmol. 1995;113(7) 870-874.

15. Argento C, Cosentino MJ, Tytiun A, et al. Corneal ectasia after laser in situ keratomileusis. J Cataract Refract Surg. 2001;27(9):1440-1448.

16. Swinger CA, Barraquer JI. Keratophakia and keratomileusis - clinical results. Ophthalmology. 1981;88(8):709-715. 
17. Jabbur NS, Stark WJ, Green WR. Corneal ectasia after laser-assisted in situ keratomileusis. Arch Ophthalmol. 2001;119(11):1714-1716.

18. Joo CK, Kim TG. Corneal ectasia detected after laser in situ keratomileusis for correction of less than -12 diopters of myopia. $J$ Cataract Refract Surg. 2000;26(2):292-295.

19. Koch DD. The riddle of iatrogenic keratectasia. J Cataract Refract Surg. 1999;25(4):453-454.

20. Lafond G, Bazin R, Lajoie C. Bilateral severe keratoconus after laser in situ keratomileusis in a patient with forme fruste keratoconus. J Cataract Refract Surg. 2001;27(7):1115-1118.

21. Leung AT, Rao SK, Lam DS. Delayed onset keratectasia after LASIK. J Cataract Refract Surg. 1999;25(8):1036-1037.

22. McLeod SD, Kisla TA, Caro NC, McMahon TT. Iatrogenic keratoconus: corneal ectasia following laser in situ keratomileusis for myopia. Arch Ophthalmol. 2000;118(2):282-284.

23. Seiler T, Koufala K, Richter G. Iatrogenic keratectasia after laser in situ keratomileusis. J Refract Surg. 1998;14(3):312-317.

24. Seiler T, Quurke AW. Iatrogenic keratectasia after LASIK in a case of forme fruste keratoconus. J Cataract Refract Surg. 1998;24(7): 1007-1009.

25. Randleman JB, Trattler WB, Stulting RD. Validation of the Ectasia Risk Score System for preoperative laser in situ keratomileusis screening. Am J Ophthalmol. 2008;145(5):813-818.

26. Binder PS. Analysis of ectasia after laser in situ keratomileusis: risk factors. J Cataract Refract Surg. 2007;33(9):1530-1538.

27. Brautaset RL, Nilsson M, Miller WL, Leach NE, Tukler JH, Bergmanson JP. Central and peripheral corneal thinning in keratoconus. Cornea. 2013;32(3):257-261.

28. Kim HY, Budenz DL, Lee PS, Feuer WJ, Barton K. Comparison of central corneal thickness using anterior segment optical coherence tomography vs ultrasound pachymetry. Am J Ophthalmol. 2008;145(2): $228-232$.

29. Randleman JB, Woodward M, Lynn MJ, Stulting RD. Risk assessment for ectasia after corneal refractive surgery. Ophthalmology. 2008;115(1):37-50.

30. Randleman JB, Russell B, Ward MA, Thompson KP, Stulting RD. Risk factors and prognosis for corneal ectasia after LASIK. Ophthalmology. 2003;110(2):267-275.
31. Giledi O, Daya SM. Unexpected flap thickness in laser in situ keratomileusis. J Cataract Refract Surg. 2003;29(9):1825-1826.

32. Spadea L, Palmieri G, Mosca L, Fasciani R, Balestrazzi E. Iatrogenic keratectasia following laser in situ keratomileusis. J Refract Surg. 2002;18(4):475-480.

33. Javaloy Estañ J, Vidal MT, Quinto A, De Rojas V, Alió JL. Quality assessment model of 3 different microkeratomes through confocal microscopy. J Cataract Refract Surg. 2004;30(6):1300-1309.

34. Kanellopoulos AJ, Asimellis G. Three-dimensional LASIK flap thickness variability: topographic central, paracentral and peripheral assessment, in flaps created by a mechanical microkeratome (M2) and two different femtosecond lasers (FS60 and FS200). Clin Ophthalmol. 2013;7:675-683.

35. Moshirfar M, Gardiner JP, Schliesser JA, et al. Laser in situ keratomileusis flap complications using mechanical microkeratome versus femtosecond laser: retrospective comparison. J Cataract Refract Surg. 2010;36(11):1925-1933.

36. Duffey RJ, Leaming DV. US trends in refractive surgery: 2012 ASCRS survey. Presented at: American Society of Cataract and Refractive Surgery Annual Meeting; April 17-21; 2012; San Francisco, CA. Available from: http://www.duffeylaser.com/physicians_resources.php. Accessed July 25, 2013.

37. Vaddavalli PK, Yoo SH. Femtosecond laser in-situ keratomileusis flap configurations. Curr Opin Ophthalmol. 2011;22(4):245-250.

38. Klein SR, Epstein RJ, Randleman JB, Stulting RD. Corneal ectasia after laser in situ keratomileusis in patients without apparent preoperative risk factors. Cornea. 2006;25(4):388-403.

39. Spadea L, Cantera E, Cortes M, Conocchia NE, Stewart CW. Corneal ectasia after myopic laser in situ keratomileusis: a long-term study. Clin Ophthalmol. 2012;6:1801-1813.

40. Chen MC, Lee N, Bourla N, Hamilton DR. Corneal biomechanical measurements before and after laser in situ keratomileusis. J Cataract Refract Surg. 2008;34(11):1886-1891.

41. Twa MD, Nichols JJ, Joslin CE, et al. Characteristics of corneal ectasia after LASIK for myopia. Cornea. 2004;23(5):447-457.

42. Condon PI, O'Keefe M, Binder PS. Long-term results of laser in situ keratomileusis for high myopia: risk for ectasia. J Cataract Refract Surg. 2007;33(4):583-590.
Clinical Ophthalmology

\section{Publish your work in this journal}

Clinical Ophthalmology is an international, peer-reviewed journal covering all subspecialties within ophthalmology. Key topics include: Optometry; Visual science; Pharmacology and drug therapy in eye diseases; Basic Sciences; Primary and Secondary eye care; Patient Safety and Quality of Care Improvements. This journal is indexed on

\section{Dovepress}

PubMed Central and CAS, and is the official journal of The Society of Clinical Ophthalmology (SCO). The manuscript management system is completely online and includes a very quick and fair peer-review system, which is all easy to use. Visit http://www.dovepress.com/ testimonials.php to read real quotes from published authors. 